\title{
The Factors Predicting Depression of Expatriates in Turkey
}

\author{
Olga S. Hünler \\ İzmir University of Economics, İzmir, Turkey
}

\begin{abstract}
The purpose of the present study is to investigate the factors related to the depressive symptomatology of expatriates living in İzmir. Although Turkey is better known as an emigration country, the number of foreign employees in Turkey has been growing. Even though the number of expatriates has increased, very few studies have been conducted with expatriates as the target group. The results revealed that desire for going back to home country significantly predicts depressive symptoms. On the other hand, being self-efficacious is significantly but inversely related to the symptoms of depression. These findings will be discussed in the light of the current literature.
\end{abstract}

Keywords: expatriate, migration, depression, self-efficacy

\section{Introduction}

The rapid globalization in today's world requires higher understanding of the needs of expatriates and immigrants. Even though Turkey has been known as an emigrating country, according to the 2000 census population, 234,111 legal immigrants from several countries have been reported residing in Turkey. Furthermore, refugees, asylum seekers, and illegal immigrants were not included in this number.

Immigrating to a new culture could be one of the most stressful experiences. Several factors could contribute to the development of psychological problems in immigrating populations. Interaction of biological, social, and psychological factors could influence the prevalence and the incidence of psychological problems (Bhugra \& Becker, 2005). Depression is one of the most common psychological problems among the immigrant groups (Van der Wurff et al., 2004; Vega, Kolody, Valle, \& Hough, 1986; Vega, Kolody, \& Valle, 1987). Several studies demonstrated that several personal and personality factors might be related to depression in immigrant populations. Some of these factors are education, income, and employment status (Vega, Kollody, \& Valle, 1987), acculturative stress (Hovey, 2000), being female (Abouguendia \& Noels, 2001; Bengi-Arslan, Verhulst, \& Crijnen, 2002; Hovey, 2000; Hünler, 2009; Ritsner, Ponizovsky, Nechamkin, \& Modai, 2001), independent and interdependent self-construals (Berry, 2001; Hyun, 2001; Lam, 2005).

Even though the relations between depression and self-efficacy have been studied widely, those relationships have not been investigated sufficiently through the acculturation experience of the immigrant populations. Bosscher and Smit (1998) defined self-efficacy as "the belief of a person in his or her ability to organize and execute certain behaviors that are necessary in order to produce given attainments" (p. 339). Cheung and Sun (2000) argued that self-efficacy is - among the other psycho-social factors - one of the key factors contributing depression and anxiety. Self-efficacy plays a critical role for exercising control over one's motivation. Individual's judgment about their abilities to control life-affecting events is quite central for human

Olga S. Hünler, Ph.D., assistant professor, Department of Psychology, İzmir University of Economics. 
agency (Bandura, 1989). Highly self-efficacious individuals prefer to engage in more challenging tasks and set themselves difficult goals and adhere to them. After they plan their actions, they invest time and energy to fulfill them even they face the challenges that they remain committed to their goals (Luszczynska, Gutierrez-Don, \& Schwarzer, 2005). On the other hand, low self-efficacy expectation is found as related with the symptoms of depression (Fiori, Mcilvane, Brown, \& Antonucci, 2006; Jenkins, Goodness, \& Buhrmester, 2002; Muris, 2001; Muris, Schmidt, Lambrichs, \& Meesters, 2001).

In one of the very limited number of studies about self-efficacy and depression relationship in minority population, Locke, Newcomb, Duclos, and Goodyear (2007) observed the protective role of high general self-efficiency on the symptoms of dysphoria among Latina teenagers.

Self-efficacy is "a self-evaluation of one's competence to successfully execute a course of action necessary to reach desired outcomes" (Lazarus \& Folkman, 1984, p. 678). Lazarus and Folkman (1984) argued that individuals evaluate environmental demands depending on their personal beliefs-like self-efficacy. If individuals with a high self-efficacy tended to interpret environmental events as a challenge rather than a threat, in case of migration, they could accept adaptation to a new country as a challenge. As a result, this approach is expected to result in better psychological adaptation to the stressful demands of acculturation.

Proactive attitude as a psychological construct is related to other personality variables, such as locus of control, self-determination, optimism, hope, and self-efficacy (Schmitz \& Schwarzer, 1999). It should be added that, even though proactive attitudes are strongly associated with these variables, it is conceptually distinct. According to Schwarzer's Proactive Coping Theory (1999), individuals who use proactive coping strategies try to improve the quality of their lives and their environment. Instead of reacting to the difficulties, they could accumulate and mobilize their resources when needed (Schmitz \& Schwarzer, 1999).

According to Greenglass and Fiksenbaum (2009), proactive coping is different from traditional forms of coping in different ways. Firstly, proactive coping is future oriented, traditional coping is past oriented. Secondly, proactive coping is a goal management technique, but traditional coping is a risk management one. Proactive individuals assess risks and possibilities of the future and approach them as a challenge. Finally, because of approaching the future events as a challenge instead of a threat, proactive coping is more positive than traditional coping strategies.

If proactive individuals are described as confident about their personal and social resources and able to mobilize them when they face incoming challenges, in that case, proactive immigrants could understand the possible difficulties to adjust to a new culture and they could mobilize their resources in order to deal with the demands of acculturation. Thereby, they might experience fewer or no signs of psychological problems due to acculturative stress.

Beside the personality factors, there are some social and migration related factors, which might be influential on the psychological well-being of immigrants. Social skills, negative or positive life events prior and post migration experiences, social support, coping skills, proximity to group members, perceptions about the host culture, acculturation orientation, and causes of migration might influence the adjustment to immigration (Berry, Kim, Minde, \& Mok, 1987; Bhugra, 2003; Saez-Diago \& Bernal, 2003; Ponizovsky, Ritsner, \& Modai, 2000; Virta, Sam, \& Westin, 2004).

Acculturation orientation of the immigrants is one of the prominent variables that have been investigated to explain the psychological health of the immigrants. Research on acculturation started with the exploration of the effects of European colonization on indigenous people, later developing into the examination of the effects 
of either voluntary or involuntary immigration on ethnic groups (Berry, 2001). Even though new measurement techniques of acculturation are ever-evolving and there are ongoing debates about its conceptualization, the concept of acculturation is still a central part of cross-cultural psychology.

Acculturation studies started with the unidimensional approach, which presupposes a change in cultural identity along a continuum over time (Ryden, Alden, \& Paulhus, 2000). In this approach, adaptation to mainstream society has seen as a natural outcome of acculturation (Van de Vijver \& Phalet, 2004). Later, the bidimensional approach has become popular. In this approach, heritage (the culture of origin) and mainstream culture (the culture of the host society) are relatively independent from one another (Ryden et al., 2000; Berry, 2001). In bidimensional approach, one person could maintain his or her cultural identity, while adapting the culture of the host society as well.

In studies that have relied upon Berry's bidirectional acculturation strategies, integration (successfully preserved the culture of the origin and successfully adapt to the new culture) was almost always relieved significantly positive relationship with mental health outcomes (Lim, Heiby, Brislin, \& Griffin, 2002; Prilleltensky, 1993; Virta, Sam, \& Westin, 2004; Ward \& Kennedy, 1999). Furthermore, marginalization (failed to maintain heritage culture and failed to adapt the culture of the host society) generally was found to be related to the poor psychological outcomes (Berry et al., 1987; Verkuyten \& Kwa, 1994; Sam \& Berry, 1995).

Depending on the motivation, researchers identified different types of migration movements. These movements might be voluntary or involuntary, temporary or permanent. Depending on the motivation of migration and duration of stay, these groups might be called as immigrants, asylum seekers, refugees, or sojourners (Berry, 2001). In the literature, the term "expatriate" generally refers to an immigrant employee/worker who has been sent overseas by their companies (Bochner, 2006). Expatriates are long-term sojourners and eventually more or less they get in contact with the locals. In this study, however, the term "expatriate" used to explain foreign professionals who are working and residing in Turkey voluntarily.

Even though psychological difficulties expats' experience abroad has been widely studied, in Turkey, there has a limited body of knowledge about the issue. Therefore, the purpose of this study is to explore factors related to depressive complaints of expatriates who are residing in or near İzmir.

\section{Method}

\section{Participants}

Seventy-nine expatriates who are living in or near İzmir participated in this study voluntarily. Eight-page questionnaires in English were delivered to participants. Participants without intermediate level of English were eliminated from the study. Forty-four of the participants were women, 33 of them were men, and two of them did not report their gender (see Table 1). The mean age of the participants was equal to 42.8 (SD (standard deviation) $=10.9$ ) and their ages ranged between 21 and 65 (see Table 2). The majority of them were from England (30.4\%) and USA (24.1\%). Their education level ranged from illiterate to doctorate level. The mean education level was approximately equal to high school graduate.

Fifty-four of them were either married or having a partner, and 51 of their partners are residing in Turkey with them. Thirty-seven of them are having children, and 29 of their children are in Turkey with them.

Forty-three percent of the participants reported either good or perfect comprehension of spoken-Turkish, while $7.6 \%$ of them had no comprehension at all. While $32.9 \%$ of them socialized either mainly or only with 
Turkish people, only $5 \%$ of them socialized merely with foreigners. Sixty-two percent of them were either mainly or merely following non-Turkish media, and only $6.3 \%$ of them were following Turkish media only. When $24.1 \%$ of them had never considered going back to country of origin, $12.7 \%$ of them were thinking about it all the time (see Table 1).

Table 1

Frequencies and Percentages of Demographic Characteristics of the Participants

\begin{tabular}{|c|c|c|c|}
\hline Variables & & $N$ & $\%$ \\
\hline \multirow{2}{*}{ Gender } & Female & 44 & 57.1 \\
\hline & Male & 33 & 42.9 \\
\hline \multirow{3}{*}{ Nationality } & English & 24 & 31.2 \\
\hline & USA & 19 & 24.7 \\
\hline & Other & 34 & 44.1 \\
\hline \multirow{2}{*}{ Marital/Relationship status } & Married/Have a partner & 54 & 68.4 \\
\hline & Single & 25 & 31.6 \\
\hline \multirow{2}{*}{ Partner residing } & In Turkey & 51 & 94 \\
\hline & Abroad & 3 & 6 \\
\hline \multirow{2}{*}{ Children } & Yes & 37 & 48.4 \\
\hline & No & 41 & 52.6 \\
\hline \multirow{5}{*}{ Level of spoken-Turkish } & None at all & 6 & 7.6 \\
\hline & Not good & 20 & 25.3 \\
\hline & Moderate & 17 & 21.5 \\
\hline & Good & 17 & 21.5 \\
\hline & Very good & 19 & 24.1 \\
\hline \multirow{5}{*}{ People socialize with } & None of them are Turkish & 4 & 5.1 \\
\hline & Few of them are Turkish & 13 & 16.5 \\
\hline & Half of them are Turkish & 36 & 45.6 \\
\hline & Many of them are Turkish & 21 & 26.6 \\
\hline & All of them are Turkish & 5 & 6.3 \\
\hline \multirow{5}{*}{ Media use } & All foreign & 30 & 38 \\
\hline & Mainly foreign & 19 & 24.1 \\
\hline & Half foreign & 21 & 26.6 \\
\hline & Mainly Turkish & 4 & 5.1 \\
\hline & All Turkish & 5 & 6.3 \\
\hline \multirow{5}{*}{ Thinking about going back to home country } & Never & 19 & 24.1 \\
\hline & Rarely & 18 & 22.8 \\
\hline & Sometimes & 19 & 24.1 \\
\hline & Frequently & 13 & 16.5 \\
\hline & All the time & 10 & 12.7 \\
\hline
\end{tabular}

Table 2

Demographic Characteristics of the Participants

\begin{tabular}{llllll}
\hline Variable & Mean & $S D$ & Variance & Minimum & Maximum \\
\hline Age & 42.8 & 10.9 & 118.2 & 21 & 65 \\
\hline
\end{tabular}

\section{Instruments}

Demographic data sheet. In order to understand the demographic characteristics of the participants, 15 
questions were asked. These questions intended to understand the topics, such as gender of the participants, institutions where they are working, country of origin, relationship status, Turkish comprehension, socialization preferences, media use, and considering going back to their home countries.

Vancouver Index of Acculturation. The Vancouver Index of Acculturation was developed by Ryden, Alden, and Paulhus (2000) to measure heritage and mainstream culture acculturations. The original scale consisted of 20 items rated on a 9-point scale from "(1) Completely disagree" to "(9) Completely agree", however, for the coherence of the questionnaire set, a 7-point rating scale was adapted for the scale. Ryder and colleagues (2000) reported the internal consistencies of the heritage dimension as $0.91,0.92$, and 0.91 for the Chinese, East Asian, and miscellaneous samples, respectively. Similarly, the internal consistencies of the mainstream dimensions were reported as $0.89,0.85$, and 0.87 for the same samples.

GSES (General Self-efficacy Scale). GSES was developed by Sherer, Maddux, Mercadante, Prentice-Dunn, Jacobs, and Rogers (1982) to measure general self-efficacy. The short version of this scale was developed by Bosscher and Smit in 1998 and the 17-item original scale was reduced to a 12-item form. Three subscales reveled from this study: initiative, effort, and consistency. The alpha reliability for these subscales was reported as $0.64,0.63$, and 0.64 , respectively. The whole scale internal consistency was reported as 0.69 (Bosscher \& Smit, 1998).

In the original study Sherer et al. (1982) used a 14-point Likert scale ranging from "Strongly disagree" to "Strongly agree". However, in order to prevent the consistency of the questionnaire, item format switched to a 5-point Likert type scale for the present study.

PAS (Proactive Attitude Scale). PAS was developed by Schmitz and Schwarzer (1999) to measure proactive attitudes among German adults. PAS was composed of 8-Likert type questions. The whole scale internal consistency of the scale was reported as 0.79 . The 4-point response style was switched to a 5-point response style in order to prevent the coherence of the questionnaire set.

BSI-DSS (Brief Symptom Inventory-Depression Subscale). The BSI was developed by Derogatis (1992) to measure different psychological symptoms in adolescents and adults. The BSI is the short version of the SCL-90-R (Symptom Checklist-90-R), which is originally composed of 90 items loaded on nine different factors. Fifty-three items were selected from the original scale via the investigation of the highest loaded items on those factors. For the present study, the DSS of the BSI was used. The 12-item scale was converted from a 7-point response style to a 5-point response style in order to maintain the consistency with other measures of the study.

\section{Results}

\section{Correlations Among Variables}

As it can be expected, depression revealed significant and positive relation with contemplation to move back to country of origin $(r=0.42, p<0.001)$. Depression also revealed significant relations with socialization $(r=-0.23, p<0.05)$, neighbors $(r=-0.27, p<0.05)$, proactive attitudes $(r=-0.36, p<0.01)$, self-efficacy $(r=$ $-0.39, p<0.001)$, and host culture acculturation $(r=-0.33, p<0.001)$ in reverse direction (see Table 3 ).

Furthermore, the results of the correlation analysis revealed positive and significant relationship between host culture acculturation and general self-efficacy $(r=0.37, p<0.01)$, as well as between host culture acculturation and proactive attitudes $(r=0.34, p<0.01)$. Not surprisingly, considering going back to home 
country revealed significant and reverse relationship with host culture $(r=-0.51, p<0.01)$ (see Table 3 ).

Table 3

Correlations Among Variables

\begin{tabular}{|c|c|c|c|c|c|c|c|c|c|c|c|}
\hline & Age & Turkish & Soc. & Media & Neighbors & Home & PAS & GSES & $\mathrm{HCA}$ & HOCA & BSI-DSS \\
\hline Age & 1 & & & & & & & & & & \\
\hline Turkish & 0.054 & 1 & & & & & & & & & \\
\hline Soc. & -0.045 & 0.191 & 1 & & & & & & & & \\
\hline Media & 0.120 & $0.502^{* *}$ & $0.487^{* *}$ & 1 & & & & & & & \\
\hline Neighbors & 0.099 & 0.061 & $0.279^{*}$ & $0.256^{*}$ & 1 & & & & & & \\
\hline Home & -0.175 & -0.076 & $-0.317^{* *}$ & $-0.411^{* *}$ & $-0.311^{* *}$ & 1 & & & & & \\
\hline PAS & 0.076 & 0.102 & 0.074 & 0.120 & 0.152 & -0.181 & 1 & & & & \\
\hline GSES & 0.093 & 0.149 & -0.042 & 0.115 & 0.046 & -0.079 & $0.351^{* *}$ & 1 & & & \\
\hline $\mathrm{HCA}$ & 0.114 & 0.158 & -0.121 & -0.154 & -0.192 & $0.290^{* *}$ & 0.078 & 0.082 & 1 & & \\
\hline HOCA & 0.120 & 0.133 & $0.401^{* *}$ & $0.447^{* *}$ & 0.220 & $-0.508^{* *}$ & $0.369^{* *}$ & $0.342^{* *}$ & -0.023 & 1 & \\
\hline BSI-DSS & -0.109 & -0.005 & $-0.230^{*}$ & -0.110 & $-0.268^{*}$ & $0.421^{* * *}$ & $-0.346^{* *}$ & $-0.386^{* * *}$ & 0.075 & $-0.328^{* *}$ & 1 \\
\hline
\end{tabular}

Notes. Turkish $=$ Level of spoken-Turkish, Soc. $=$ Socialization preferences, Media $=$ Media use preference, Home $=$ Desire for going back to home country, PAS = Proactive Attitudes Scale, GSES = General Self-Efficacy Scale, HCA = Heritage Culture Acculturation, HOCA $=$ Host Culture Acculturation, BSI-DSS $=$ Brief Symptom Inventory-Depression Subscale. ${ }^{*}$ Correlation is significant at the 0.05 level (2-tailed); ${ }^{* *}$ Correlation is significant at the 0.01 level (2-tailed); ${ }^{* * *}$ Correlation is significant at the 0.001 level (2-tailed).

\section{Depression}

In order to understand the contributions of independent factors on dependent variable (depression), multiple regression analysis was conducted. Due to the restricted sample size, only four independent variables, which revealed the strongest correlation with dependent variable, were selected for the regression analysis.

The results revealed that desire for going back to home country significantly predicts depressive symptoms $(\beta=0.38, p<0.01)$. On the other hand, being self-efficacious is significantly but inversely related to the symptoms of depression $(\beta=-0.31, p<0.01)$ (see Table 4$)$.

Table 4

Regression Analysis for Depression

\begin{tabular}{|c|c|c|c|c|c|c|c|}
\hline Predictor & $R$ & $R^{2}$ change & $F^{1}$ & $B$ & $\beta$ & $t$ & $S E$ \\
\hline Going back to home country & 0.58 & 0.33 & $9.13^{*}$ & 0.20 & 0.38 & $3.45^{* *}$ & 0.06 \\
\hline Proactive attitudes & & & & -0.17 & -0.18 & -1.74 & 0.10 \\
\hline Self-efficacy & & & & -0.37 & -0.31 & $-2.89^{* *}$ & 0.13 \\
\hline Host culture acculturation & & & & 0.04 & 0.04 & 0.32 & 0.12 \\
\hline
\end{tabular}

Notes. ${ }^{1} d f=78 ;{ }^{*} p<0.001 ;{ }^{* *} p<0.01$.

\section{Discussion}

The results of this study demonstrated that thinking about going back to home country and low self-efficacy are related to the increased depressive symptomatology of expatriates. Desire for going back to one's home country might suggest discontent with the current conditions. Factors, such as acculturative adaptation difficulties, cultural distance, socio-economic difficulties, or family problems might all contribute to this wish. Beside immigrants' adjustment difficulties to a new culture, host culture's expectations about immigrants' acculturation might also contribute to elevated acculturative stress (Jasinska-Lahti, Liebkind, 
Horenczyk, \& Schmitz, 2003) which may contribute to the desire for going back. Similarly, in this study, desire to return was found related with socializing with Turkish people and using Turkish media rather than foreign ones.

Sometimes, immigrants wish to return their home countries because of disappointment and frustration that they have experienced in host country. However, sometimes return migration occurs after immigrants achieve their prior plans (Arowolo, 2000). In a study conducted with Swedish and Finnish about the return migrants in Finland, it has been found that males, highly educated and younger immigrants return more. In addition, people who were living with their partners before migration, tended to go back to the country of origin more than the people who were living alone or living with their families (Finnäs, 2003). In another study conducted with African immigrants, one of the main reasons revealed for return migration was economic opportunities. Immigrants, who could afford to buy or regain the land rights and could support themselves by farming, returned their home countries instead of staying in the host country permanently (Peil, 1995). Sometimes, immigrants choose to return home when they guarantee their safety, accommodation, and social recognition in their home countries (Arowolo, 2000). Gmelch (1980) argued that return migration does not always happen due to economic reasons. Sometimes, immigrants prefer to be close to their family and longtime friends.

When we try to understand immigrants' desire for going back to their home countries, negative experiences with host culture, as well as the attributions about those negative experiences might be critical. Zajacova, Lynch, and Espenshade (2005) argued that when individuals interpret the environmental demands as a challenge rather than a threat, they are more likely to choose the most effective coping strategy to handle the demands of the situation. Expatriates who have high self-efficacy could be handling the difficulties of cultural adjustment as a challenge and could be using the most efficient coping mechanism. However, expatriates with low self-efficacy might be unable to operate the effective strategies, while they are dealing with migration related issues, such as cultural adjustment, being away from the family members, dealing with daily hassles in a foreign setting.

Even though proactive attitudes revealed significant correlation with depression, it does not have a predictive power. However, Uskul and Greenglass (2005) observed that proactive coping emerged as a significant predictor of depression and subjective well-being of Turkish immigrants in Canada. This difference might happen due to using different measurement devices or the limited sample size of the presented study.

The most important weakness of the presented study is its limited sample size. Even though the response rate of participants for this study is acceptable, it was difficult to get in contact with the target population. Although İzmir is one of the biggest cities of Turkey, the expat community living in or around İzmir does not have a high-density population.

Further studies with a larger sample size and participant expatriates from different locations of Turkey would be beneficial in order to understand the relationship between personality factors, demographic factors, acculturation, and depression.

\section{References}

Abouguendia, M., \& Noels, K. A. (2001). General and acculturation-related daily hassles and psychological adjustment in firstand second-generation South Asian immigrants to Canada. International Journal of Psychology, 36, 163-173.

Arowolo, O. O. (2000). Return migration and the problem of reintegration. International Migration, 38, 59-82.

Bandura, A. (1989). Social cognitive theory. In R. Vasta (Ed.), Annals of child development: Six theories of child development (Vol. 6, pp. 1-60). Greenwich, C. T.: JAI Press. 
Bengi-Arslan, L., Verhulst, F. C., \& Crijnen, A. A. M. (2002). Prevalence and determinants of minor psychiatric disorder in Turkish immigrants living in the Netherlands. Social Psychiatry and Psychiatrical Epidemiology, 37, 118-124.

Berry, J. W. (2001). A psychology of immigrants. Journal of Social Issues, 57, 615-631.

Berry, J. W., Kim, U., Minde, T., \& Mok, D. (1987). Comparative studies of acculturative stress. International Migration Review, 21, 491-511.

Bhugra, D. (2003). Migration and depression. Acta Psychiatrica Scandinavica, 108, 67-72.

Bhugra, D., \& Becker, M. A. (2005). Migration, cultural bereavement and cultural identity. World Psychiatry, 4, 18-24.

Bochner, S. (2006). Sojourners. In D. L. Sam, \& J. W. Berry (Eds.), The Cambridge handbook of acculturation psychology (pp. 181-197). N. Y.: Cambridge University Press.

Bosscher, R. J., \& Smit, J. H. (1998). Confirmatory factor analysis of the general self-efficacy scale. Behavior Research and Therapy, 36, 339-343.

Cheung, S., \& Sun, S. Y. K. (2000). Effects of self efficacy and social support on the mental health condition of mutual-aid organization members. Social Behavior and Personality, 28, 413-422.

Derogatis, L. R. (1992). Brief Symptom Inventory (BSI): Administration, scoring, and procedures manual (2nd ed.). Baltimore: Clinical Psychometric Research.

Finnäs, F. (2003). Migration and return-migration among Swedish-speaking Finns. In R. Höglund, M. Jäntti, \& G. Rosenqvist (Eds.), Statistics, econometrics and society: Essays in honour of Leif Nordberg (pp. 41-54). Research Reports, No. 238. Statistics Finland, Helsinki.

Fiori, K. L., Mcllvane, J. M., Brown, E. E., \& Antonucci, T. C. (2006). Social relations and depressive symptomatology: Self-efficacy as a mediator. Aging Mental Health, 10, 227-239.

Gmelch, G. (1980). Return migration. Annual Review of Anthropology, 9, 135-159.

Greenglass, E. R., \& Fiksenbaum, L. (2009). Proactive coping, positive affect, and well-being: Testing for mediation using path analysis considerations. In J. P. Ziegelmann, \& S. Lippke (Eds.). Invited paper in European Psychologist (Special Section on Theory-Based Approaches of Stress and Coping), 14, 29-39.

Hovey, J. D. (2000). Acculturative stress, depression, and suicidal ideation in Mexican immigrants. Cultural Diversity and Ethnic Minority Psychology, 6, 134-151.

Hünler, O. S. (2009). The psychological problems of Turkish immigrants and gender differences in the Netherlands. Kadın/Woman 2000, 10, 1-26

Hyun, K. (2001). Is an independent self a requisite for Asian immigrants' psychological well-being in the U.S.? The case of Korean Americans. Journal of Human Behavior in the Social Environment, 3, 179-200.

Jasinska-Lahti, I., Liebkind, K., Horenczyk, G., \& Schmitz, P. (2003). The interactive nature of acculturation attitudes and stress among young ethnic repatriates in Finland, Israel and Germany. International Journal of Intercultural Relations, 27, 79-97.

Jenkins, S. R., Goodness, K., \& Buhrmester, D. (2002). Gender differences in early adolescents' relationship qualities, self-efficacy, and depression symptoms. Journal of Early Adolescence, 22, 277-309.

Lam, B. T. (2005). Self-construal and depression among Vietnamese-American adolescents. International Journal of Intercultural Relations, 29, 239-250.

Lazarus, R. S., \& Folkman, S. (1984). Stress, appraisal, and coping. New York: Springer.

Lim, K. V., Heiby, E., Brislin, R., \& Griffin, B. (2002). The development of the Khmer acculturation scale. International Journal of Intercultural Relations, 26, 653-678.

Locke, T. F., Newcomb, M. D., Duclos, A., \& Goodyear, R. K. (2007). Psychosocial predictors and correlates of dysphoria in adolescent and young adult Latinas. Journal of Community Psychology, 35, 135-149.

Luszczynska, A., Gutie'rrez-Doña, B., \& Schwarzer, R. (2005). General self-efficacy in various domains of human functioning: Evidence from five countries. Journal of Psychology, 40, 80-89.

Muris, P. (2001). Relationships between self-efficacy and symptoms of anxiety disorders and depression in a normal adolescent sample. Personality and Individual Differences, 32, 337-348.

Muris, P., Schmidt, H., Lambrichs, R., \& Meesters, C. (2001). Protective and vulnerability factors of depression in normal adolescents. Behavior Research and Therapy, 39, 555-565.

Peil, M. (1995). Ghanaians abroad. African Affairs, 94, 345-367.

Ponizovsky, A, Ritsner, M., \& Modai, I. (2000). Changes in psychological symptoms during the adjustment of recent immigrants. Comprehensive Psychiatry, 41(4), 289-294. 
Prilleltensky, I. (1993). The immigration experience of Latin-American families: Research and action on perceived risk and protective factors. Canadian Journal of Community Mental Health, 12, 101-116.

Ritsner, M., Ponizovsky, A., Nechamkin, Y., \& Modai, I. (2001). Gender differences in psychosocial risk factors for psychological distress among immigrants. Comprehensive Psychiatry, 42, 151-160.

Ryden, A. G., Alden, L. E., \& Paulhus, D. L. (2000). Is acculturation unidimensional or bidimensional? A head-to-head comparison in the prediction of personality, self-identity and adjustment. Journal of Personality and Social Psychology, 79, 49-65.

Saez-Diego, E., \& Bernal, G. (Eds.). (2003). Depression in ethnic minorities: Latinos and Latinas, African Americans, Asian Americans, and native-Americans. Newberry, C. A.: SAGE.

Sam, D. L., \& Berry, J. W. (1995). Acculturative stress among young immigrants in Norway. Scandinavian Journal of Psychology, 36, 10-24.

Schmitz, G. S., \& Schwarzer, R. (1999). Proaktive Einstellung von Lehrern: Konstruktbeschreibung und psychometrische Analysen (Teachers' proactive attitude: Construct description and psychometric analyses). Zeitschrift für Empirische Pädagogik, 13, 3-27.

Schwarzer, R. (1999). Proactive coping theory. Paper presented at the 20th International Conference of the Stress and Anxiety Research Society (STAR), Cracow, Poland, July 12-14, 1999.

Sherer, M., Maddux, J. E., Mercadante, B., Prentice-Dunn, S., Jacobs, B., \& Rogers, R. W. (1982). The self-efficacy scale: Construction and validation. Psychological Reports, 51, 663-671.

Uskul, A. K., \& Greenglass, E. (2005). Psychological well-being in a Turkish-Canadian sample. Anxiety, Stress and Coping, 18, 169-178.

Van deVijver, F. J. R., \& Phalet, K. (2004). Assessment in multicultural groups: The role of acculturation. Applied Psychology: An International Review, 53, 215-236.

Van der Wurff, F. B., Beekman, A. T. F., Dijkshoorn, H., Spijker, J. A., Smits, C. H. M., Stek, M. L., \& Verhoeff, A. (2004). Prevalence and risk-factors for depression in elderly Turkish and Moroccan migrants in the Netherlands. Journal of Affective Disorders, 83, 33-41.

Vega, W. A., Kolody, B., \& Valle, J. R. (1987). Migration and mental health: An empirical test of depression risk factors among immigrant Mexican woman. International Migration Review, 21, 512-530.

Vega, W. A., Kolody, B., Valle, J. R., \& Hough, R. (1986). Depressive symptoms and their correlates among immigrant Mexican women in the United States. Social Science \& Medicine, 22, 645-652.

Verkuyten, M., \& Kwa, G. A. (1994). Ethnic self-identification and psychological well-being among minority youth in the Netherlands. International Journal of Adolescence and Youth, 5, 19-34.

Virta, E., Sam, D. L., \& Westin, C. (2004). Adolescents with Turkish background in Norway and Sweden: A comparative study of their psychological adaptation. Scandinavian Journal of Psychology, 45, 15-25.

Ward, C., \& Kennedy, A. (1999). The measurement of sociocultural adaptation. International Journal of Intercultural Relations, 23, 659-677.

Zajacova, A., Lynch, S. M., \& Espenshade, T. J. (2005). Self-efficacy, stress, and academic success in college. Research in Higher Education, 46, 677-706. 